\title{
BMJ Open Examining the information needed for acceptance of deintensified screening programmes: qualitative focus groups about cervical screening in Australia
}

\author{
Rachael H Dodd (D), Brooke Nickel (D), Sally Wortley (D), Carissa Bonner (1) , \\ Jolyn Hersch (D), Kirsten J McCaffery (D)
}

To cite: Dodd RH, Nickel B, Wortley S, et al. Examining the information needed for acceptance of deintensified screening programmes: qualitative focus groups about cervical screening in Australia. BMJ Open 2019;9:e029319. doi:10.1136/ bmjopen-2019-029319

- Prepublication history and additional material for this paper are available online. To view please visit the journal (http:// dx.doi.org/10.1136/bmjopen2019-029319).

Received 21 January 2019 Revised 03 July 2019 Accepted 23 September 2019

Check for updates

(C) Author(s) (or their employer(s)) 2019. Re-use permitted under CC BY-NC. No commercial re-use. See rights and permissions. Published by BMJ.

Faculty of Medicine and Health, School of Public Health, The University of Sydney, Sydney, New South Wales, Australia

Correspondence to Dr Rachael H Dodd; rachael.dodd@sydney.edu.au

\section{ABSTRACT}

Objectives Given the changing understanding of overdiagnosis of screen detected cancers and advances in technology to detect and prevent cancer, updating and scaling back cancer screening programmes is becoming increasingly necessary. The National Cervical Screening Programme (NCSP) in Australia was recently deintensified, with the changes implemented in December 2017. This study examines women's understanding and acceptance of the renewed screening protocol and how such changes can be communicated more effectively.

Design Focus groups structured around a presentation of information about the renewed NCSP, with discussions of the information facilitated throughout. Qualitative data analysis was conducted.

Setting Australia

Participants Six focus groups were conducted in November 2017 with a community sample of 49 women aged 18-74.

Results Women demonstrated little or no awareness of the upcoming screening changes in the period just before they occurred. Women expressed most concern and fear that the increased screening interval (from 2 to 5 years) and later age of first screening (from age 18 to 25 years) could lead to missing cancers. Concerns about exit testing were less common. Understanding of the natural history and the prevalence of both human papillomavirus and cervical cancer, and the nature of the new test (catching it 'earlier') was key to alleviate concerns about the increased screening interval.

Conclusions Deintensifying screening programmes should be accompanied by clear and coherent communication of the changes, including the rationale behind them, to limit concerns from the public and facilitate acceptance of renewed programmes. In this case, understanding the biology of cervical cancer was crucial.

\section{INTRODUCTION}

Understanding of the benefits and harms of cancer screening programmes has changed radically over the past 10 years with growing evidence of overdiagnosis and overtreatment of screening detected cancers. ${ }^{1}{ }^{2}$ As health technology advances to offer new screening tests, treatments and methods of cancer

\section{Strengths and limitations of this study}

- These findings make an important and timely contribution to the potential communication strategies for countries updating their national cervical screening programme.

- The qualitative design of the study allowed us to explore in depth the views and understanding of women of eligible screening age, as well as observing how women communicated the reasons behind the changes to each other.

- As this was a qualitative study, we cannot express the findings as generalisable across the whole population and we could only include English-speaking women due to the nature of the methodology.

- Additional information may have helped reassure women further that there are processes in place for dealing with exceptional circumstances and it is not a one size fits all approach.

prevention (eg, vaccination), the need to review and update screening programmes to ensure the benefits outweigh the harms has never been more pressing. Wilson and Jungner provided a set of principles to guide the practice of screening for disease, based around early detection and treatment, ${ }^{3}$ and already four decades ago, recognised that we must avoid causing harm to those who do not need treatment. There is now an increased focus on ethical principles and acceptability when developing or refining existing screening programmes, ${ }^{4}$ and awareness that screening programmes may need to be deintensified to ensure health benefits outweigh potential harms such as overdiagnosis and overtreatment as evidence changes. ${ }^{5}$

A recent example of deintensification of cancer screening comes from Australia, where the National Cervical Screening Programme (NCSP) was revised in 2017 to include an older age of invitation for screening, less frequent testing and primary human papillomavirus 
Table 1 The changes implemented to the Australian National Cervical Screening Programme on 1 December $2017^{6}$

\begin{tabular}{|c|c|c|}
\hline Change & New programme (2017) & Old programme (1991-2017) \\
\hline Test technology & $\begin{array}{l}\text { The Cervical Screening Test takes cells from the cervix } \\
\text { to test for HPV infection }\end{array}$ & $\begin{array}{l}\text { The Pap test took cells from the } \\
\text { cervix and examined these cells for } \\
\text { physical changes }\end{array}$ \\
\hline Interval & The Cervical Screening Test is every 5 years & A Pap test every 2 years \\
\hline Age & $\begin{array}{l}\text { Women will be invited for a Cervical Screening Test from } \\
\text { the age of } 25 \text { years }\end{array}$ & $\begin{array}{l}\text { Cervical screening began at } 18 \text { years } \\
\text { of age }\end{array}$ \\
\hline $\begin{array}{l}\text { Screening pathway: HPV } \\
\text { negative result }\end{array}$ & Screen again in 5 years time & - \\
\hline $\begin{array}{l}\text { Screening pathway: HPV } \\
\text { positive }(16 / 18)\end{array}$ & $\begin{array}{l}\text { Test cells using liquid-based cytology and refer for } \\
\text { colposcopy }\end{array}$ & - \\
\hline
\end{tabular}

HPV, human papillomavirus.

(HPV) screening (table 1). A national school-based programme for the HPV vaccination was introduced in 2007 for school-aged girls (aged 12-13) plus a 2-year catch up programme for girls aged 13-26 and in 2013 for school-aged boys. Current national uptake rates for three doses are $80.2 \%$ for females and $75.9 \%$ for males. ${ }^{6}$ The changes encompassed new recommendations based on evidence of potential harms attributed to the previous screening regimen, ${ }^{7}$ as well as the changing landscape due to the uptake of the HPV vaccination and the development of new screening technology.

Research has shown internationally that public response to reducing cancer screening programmes has been very negative $^{8}$; most notably in the USA, where proposed changes to breast screening in 2009 were ultimately retracted due to the public backlash. ${ }^{9}$ Our own research to the proposed changes to the Australian NCSP identified strong concerns about the increased interval between cervical screens ${ }^{1011}$ principally due to the perception that this would miss cancers and put women's lives at risk.

When implementing any major revisions to a screening programme, it is important to understand how best to communicate the changes so that people understand and accept the reasons behind it, and to ensure their confidence in the programme is not undermined. This is particularly important if the changes involve deintensification of screening. The changes to the Australian NCSP provided a timely opportunity to explore women's reactions to deintensifying a cancer screening programme and to examine how the reasons for these changes could be effectively communicated. The study aimed to explore women's understanding of the renewed programme and its acceptability, with the view of generating insights to guide communication about deintensification of future national screening programme changes in other countries.

\section{METHODS}

Participants

The focus groups were conducted with a community sample of Australian women aged 18-74; those in the age range for which the NCSP (prior and renewed programme) is the most relevant.

Participants were contacted via telephone by a fully independent market and social research company (Taverner Research), who used random landline and location known mobile samples from Sydney. To gain a diverse range of perspectives, we used purposive sampling to ensure inclusion of women with varying levels of education and prior participation in screening (including women up to date and overdue for screening in all age groups). We excluded women not fluent in English and women who had ever personally been diagnosed with cervical cancer. Taverner interviewers briefly introduced the study, assessed eligibility and availability, and asked respondents whether they would be willing to receive more information about the study. Eligible women who had verbally agreed to being contacted by the research team were emailed a Participant Information Statement and Consent Form. RHD contacted potential participants to confirm their interest and eligibility and confirmed participation in the focus groups.

\section{Design}

Six focus groups were conducted at three locations across Sydney, with 5-10 women in each group, to explore the views towards the renewed Australian NCSP among women of screening eligible age. Data collection took place in 
November 2017. Focus groups were facilitated by RHD and included an additional researcher as a moderator (BN, SW, $\mathrm{CB}$ and $\mathrm{JH})$. Participants were given a $\$ \mathrm{~A} 100$ gift card for reimbursement towards time and travel costs.

The focus groups were structured around a presentation of the changes to the NCSP and the rationale for these changes in order to facilitate discussion about what information is important to communicate to women to enable them to understand about the changes. This format gave participants the opportunity to ask questions and discuss the changes among themselves throughout. This enabled us to identify areas which may need to be communicated more clearly and to explore how women themselves understood and then explained the changes which were of particular concern to each other.

The groups were split according to age (18-30, 31-50 and 51-74years) as it was anticipated that views and preferences for information might vary as the changes to the screening programme differed by age group.

\section{Patient and public involvement}

We involved a consumer representative (patient advocate) from Health Consumers New South Wales in developing and reviewing study materials, as well as piloting the focus groups. A patient advocate and members of the public were involved in piloting of the materials and study participants were community women recruited from the general Australian public. A lay summary of the results will be sent to all participants who indicated they wanted to receive these.

\section{Presentation and discussion content}

The presentation (online supplementary material) was developed by the research team, which included a consumer representative and was reviewed by an independent expert team of researchers and clinicians. A summary outline of the presentation is included in box 1 . This presented the information available on the Australian Department of Health NCSP website ${ }^{12}$ at the time of development (September/October 2017) about the changes to the NCSP. We also presented some information developed by the research team to put some of the information into context; for example, presenting women with figures of incidence and mortality since the NCSP had been introduced and explaining the accuracy of the HPV test compared with the Pap test.

Throughout the group discussions, women were encouraged to share their thoughts about the information presented and how easy they found the information to understand. The presentation content and types of questions we used to guide the discussions are summarised in online supplementary information. We also encouraged women to ask questions throughout, while making it clear that we would initially be simply noting down the questions and would answer any questions still outstanding (ie, not answered by the intervening information presented) at the end.

\section{Box 1 Outline of the presentation}

1. Introduction to the renewed National Cervical Screening Programme-information taken from the Department of Health website (accessed September/October 2017).

2. Concerns already raised by women about the changes.

3. Answers to frequently asked questions

A. Why is cervical screening changing?

B. What should women do between now and 1 December 2017 ?

C. How will the new Cervical Screening Test work?

D. Can I have the new Cervical Screening Test now?

E. Why will the screening age change to starting at 25 years of age?

F. Should women less than 25 years of age participate in cervical screening between now and 1 December 2017 when the renewed programme is implemented?

G. How will women be invited to screen using the new Cervical Screening Test?

H. When should I stop cervical screening?

I. Will cervical screening prevent all cervical cancers?

J. What is human papillomavirus (HPV)?

K. How did I get HPV?

L. What is the relationship between HPV and cervical cancer?

M. Do I still need to screen if I have received the HPV vaccine?

N. Will the new Cervical Screening Test replace the vaccination programme?

4. Further information about the changes developed by the research team
A. Why is cervical screening changing?
B. National Cervical Screening Register
C. Change: Test
D. Change: Timing
E. Change: Age
F. Exit test
G. Old versus new programme
$\mathrm{H}$. What happens if I have a positive HPV test?

\section{Analysis of qualitative data}

All sessions were audio recorded and professionally transcribed verbatim. Transcribed focus groups were managed using NVivo V.11. ${ }^{13}$ Thematic analysis was conducted to identify main themes that captured the views of women about the changes to the NCSP, and which information presented was found to be reassuring about particular concerns or helped them understand the rationale for the changes. The initial coding framework was developed by RHD, with input from KM.

The same framework was used by two researchers (RHD and $\mathrm{BN}$ ) to analyse three transcripts each for themes and codes which focused around women's understanding of the rationale behind the changes to the NCSP. These themes and codes were developed and applied to the data, and through numerous meetings an agreement was made on the overarching concepts that were important for women's understanding and acceptance of the changes and the information they needed to address concerns. The framework with which to interpret the data was discussed with $\mathrm{KM}$, and the broader project team had input into the interpretation of the results. The research team members 
work in the field of public health, with a special interest in reducing overdiagnosis and overtreatment.

\section{Quantitative measures}

Brief written questionnaires were administered before and after each focus group. The first questionnaire included demographic questions, questions about cervical cancer and cervical screening, and intentions to go for cervical screening in the future. The second questionnaire (following the presentation) aimed to assess what knowledge and understanding women had taken from the focus groups using a series of multiple-choice items developed for this study, and again asked their intentions to go for cervical screening in the future. These are reported descriptively in the manuscript.

\section{RESULTS}

\section{Sample characteristics}

Forty-nine women participated in six focus groups (table 2). Forty-one had previously attended for cervical screening, with eight not yet having been invited. Of the 41 who had attended screening, 28 were up to date and 13 were overdue. The sample was diverse with regard to education, employment and country of birth. Focus groups lasted between 71 and 103 minutes. A minority of women verbally indicated they had heard something about the changes being made to the NCSP, with the increased interval between tests and later starting age most commonly remembered by those women.

\section{What information addresses women's concerns?}

Following the education session about the changes to the programme, we present the three key concepts that were (a) important for women to understand and accept the programme changes (b) that women found reassuring about their particular concerns: (1) Natural history, (2) Incidence and (3) Transition to the new programme (Natural history, Incidence, Transition (NhIT).

\section{Natural history and slow development of cervical cancer}

Women were concerned and confused about what it means to have HPV, the increased interval between screening tests, and the new test. They were reassured by information explaining the natural history of cervical cancer, particularly the time it takes for HPV to develop into cervical cancer.

Knowledge of HPV among women was fairly low, even in the focus groups with younger women where many of the women had received the HPV vaccine in school. Women had many questions about HPV, including how it is transmitted and whether it is cleared from the body or lies dormant.

Some of the focus groups likened HPV to cold sores or herpes. Giving women information about HPV helped them realise that HPV was very common and not serious unless it progresses. The information also helped women understand that their immune system can clear HPV by

\begin{tabular}{|c|c|}
\hline Sample $(n=49)$ & n (\%) \\
\hline \multicolumn{2}{|l|}{ Age } \\
\hline 18-30year olds & $16(32.7)$ \\
\hline $31-50$ year olds & $13(26.5)$ \\
\hline $51-74$ year olds & $20(40.8)$ \\
\hline \multicolumn{2}{|l|}{ Marital status } \\
\hline Married/living with partner & $23(46.9)$ \\
\hline Divorced/separated & $8(16.3)$ \\
\hline Widowed & $1(2.0)$ \\
\hline Single & $16(32.7)$ \\
\hline Missing & $1(2.0)$ \\
\hline \multicolumn{2}{|l|}{ Children } \\
\hline Yes & $24(49.0)$ \\
\hline No & $24(49.0)$ \\
\hline Missing & $1(2.0)$ \\
\hline \multicolumn{2}{|l|}{ Family history of cervical cancer } \\
\hline Yes & $1(2.0)$ \\
\hline No & 46 (93.9) \\
\hline Missing & $2(4.1)$ \\
\hline \multicolumn{2}{|l|}{ Country of birth } \\
\hline Australia & $30(61.2)$ \\
\hline Europe & $5(10.2)$ \\
\hline Asia & $10(20.4)$ \\
\hline Other & $4(8.2)$ \\
\hline \multicolumn{2}{|l|}{ Education } \\
\hline University degree & $22(44.9)$ \\
\hline Diploma or trade certificate & $10(20.4)$ \\
\hline High school certificate & $11(22.4)$ \\
\hline School certificate & $3(6.1)$ \\
\hline Missing & $3(6.1)$ \\
\hline \multicolumn{2}{|l|}{ Employment } \\
\hline Working full time & $20(40.8)$ \\
\hline Working part time & $12(24.5)$ \\
\hline Retired & $10(20.4)$ \\
\hline Not in paid work & $6(12.2)$ \\
\hline Missing & $1(2.0)$ \\
\hline \multicolumn{2}{|l|}{ Last Pap smear } \\
\hline Up-to-date (<2 years ago) & $28(57.1)$ \\
\hline Overdue (2+ years ago) & $13(26.5)$ \\
\hline Missing & $8(16.3)$ \\
\hline
\end{tabular}

itself, often without intervention (Q1; table 3). However, for a couple of women, this information led them to wonder if it was worth having the test at all if HPV was not that serious and the incidence of cervical cancer was so low (Q2).

Women's concerns about the screening interval focused mostly on the potential of 'missing cancers' due 
Table 3 Quotes from focus groups to support the themes

\section{Code Reference}

Q1 'But for me it almost kind of dumbed down the reason for the test. You can get it, you have to be sustained, right, persistent exposure to the virus before you get the full cancer, cervical cancer. And also you might clear itself in many cases. So it's actually very reassuring that it's not that serious a condition. That's what I got from that really.' (FG6, 31-50 years old)

Q2 'The only one thing for me is like they actually, again dumbed down the seriousness of HPV to me. 'Cause 2 women in 100 000, I was like, oh, that's not too bad. So you're going to screen the whole of the nation of women to detect two possibilities in 100 000. That's what I got from that.' (FG6, 31-50 years old)

Q3 'Well, I guess if it takes a long time, up to 10 years, for the HPV virus to affect the cells then you might detect it 12 in a year and then it's going to be a number of years until it actually affects you.' (FG2, 18-30year olds)

Q4 'But now it's going to pick up the... the infected, um, HPV infection before it gets to abnormal cells.' (FG1, 51-74 year olds)

Q5 'It's looking for different cells which take, is it 10 years to develop into a cancerous cell, which kind of makes sense to have it every 5 years. Um, to test it every 5 years 'cause if it's going to develop it's already half way developed and not even to a cancerous cell.' (FG5, 18-30 years old)

Q6 'Ok. So everyone will get HPV testing, then if they find specific strains then they'll look for (abnormal) cells.' (FG2, 18-30year olds)

Q7 'I understand the 70-74 now because they say it doesn't develop for 10 years anyway. And once they make sure that the 70-74 year olds are safe before they even exit.' (FG3, 31-50year olds)

'....the way we live our life has changed and I think younger people really aren't as, um... aware, I think, of their well-being and how important it is when they are young. And how quickly we grow old.' (FG1, 51-74 year olds)

Q9 'Maybe they weren't finding as many... cancer diseases under the age of 25?' (FG5, 18-30year olds)

Q10 'I felt the, the thing that made me a bit calmer though was that it said that there's been no change in, um, deaths or, um, I think picking up cancer in women aged 20-25 or something since they've had a screening program. So it made me feel a bit calmer about moving the age to 25. Seems legit.' (FG2, 18-30 years old)

Q11 'I think because it clears up on its own. So I think there was that point about over-detection, so it does clear up. 14 So if you are tested every two years and you have it then it could, if like... then they might, they might, um, treat it. But it might, would have cleared up on its own potentially.' (FG2, 18-30year olds)

Q12 'Can I just ask why it cuts out at 74? Is the incidence low, or it's just too painful, or it's not worth it?' (FG4, 51-74 year olds)

Q13 'The actual procedure is exactly the same for the patient, I guess you can say. The person being tested. And it's 15 just what happens after that's changing.' (FG2, 18-30 years old)

Q14 'But if you go and something is detected, um, do you have to wait 5 years for them... like if they think 15 something's detected will we have to wait for another 5 years for them to say, oh yes, something has been detected now, but it may have been there before but we don't know, sort of thing? How that's going to sort of go?' (FG5, 18-30year olds)

HPV, human papillomavirus.

to the time between tests being increased. Understanding that HPV caused most cervical cancers, and that the virus can take around 10 years to develop into cervical cancer, helped to reassure women (Q3).

The new HPV test was referred to in the government-provided programme renewal information as the 'cervical screening test' and it took some time during the focus groups for women to realise that the test was going to be different in the new programme. Women's concerns about the new test were around whether it was safe, accurate and they wanted more information. Once women understood that the new test was to detect HPV, which causes most cervical cancers, women were reassured that this test was detecting something earlier, 'like a step ahead' (Q4).
Women from most focus groups understood the information about the natural history of cancer and used this to interpret the rationale behind the increased screening interval (Q5). Some focus group participants quickly grasped the process of the new test and explained this in a simple way to each other $(\mathrm{Q} 6)$.

Older women in the sample expressed concern about the exit test, about what this meant for them and why it was decided women would leave the programme between 70 and 74 years of age. Information about the slow progression of cervical cancer helped to reassure women about the reasons for the exit test $\left(Q^{7}\right)$. 
Incidence of cervical cancer

Women in the younger age groups were mainly concerned about the later start age, whereas women in the older age groups were concerned about both younger and older women, and also concerned that young women were not as aware of their health as they should be (Q8).

All women considered younger women to be more sexually active from an earlier age 'these days', and were, therefore, worried about the time between young women commencing sexual activity and their first screening test, as they perceived them to be at greater risk of developing cervical cancer earlier.

When speculating about reasons for the later starting age, one focus group considered the number of cases in women under 25 (Q9). Crucially, presenting women with incidence data of cervical cancer in Australia showing that cervical cancer in young women was very rare (in both HPV vaccinated and unvaccinated women) and that despite screening women younger than 25 years of age for over 20 years there has been no change to the rates of cervical cancer or rates of death from cervical cancer in this age group, was key to help reassure women about the later start age of screening (Q10).

The rationale for the later starting age presented information about overdetection and one group discussed this further with questions about how HPV clears itself without need for treatment sometimes (Q11). This led some women in the group to consider the harms of immediate treatment, but in other focus groups surprise was conveyed about overtreatment and there was confusion about at what age it was better to monitor to see if abnormalities resolve themselves. Once it was explained, women did understand that the cells often got better without intervention but there was confusion about why this varied with age.

The women in the younger (18-50) age groups also expressed a desire for more evidence and more data around the incidence of cervical cancer and liked the additional graphs and tables that were included on the slides developed by the research team (see online supplementary information).

The two older age groups spent longer discussing the exit test than the younger age group. One group found it interesting how cervical screening contradicts their understanding of screening for other cancers (eg, breast and bowel), such that you get more screening as you get older (despite both these screening programme also stopping screening by 74 years of age), not less. Many of the women also tried to process the information about the exit test and what this may have meant about cervical cancer incidence in older women, wondering if the incidence is low and therefore not worth it for older women (Q12).

Transition to the new programme and the screening pathway

Many women expressed concern and confusion over how they, and other women, transition from the old to the new programme. Some women were unsure whether they would have another Pap test, or whether they would go straight to having a cervical screening test at their next test (if after 1 December 2017).

One woman explained that information may be important for those women who will be most affected by the transition period, namely women under 25 who have already received cervical screening, and also those older women who will no longer be eligible for screening in the old programme, but whom might now be invited for an exit test.

Women were reassured by the information that they should still go for their next screening test 2 years after their last test, but that this will be the new cervical screening test and providing their results were normal they would not be invited back for another 5 years. It was also important to make it clear to women that although the test would be different, the procedure for collecting the specimen would be exactly the same (Q13).

Many women initially wanted to know what happened after the test, as the information from the Department of Health did not give any information on the screening pathway (Q14).

\section{How to communicate these changes?}

In terms of how to communicate these changes, verbal explanations from your general practitioner (GP) and through schools were suggested across all groups. Additionally, younger age groups suggested focusing communication more through social media (eg, Facebook, Instagram), websites and email, and the older age groups through posters, television adverts and public awareness campaigns.

\section{Quantitative data}

Prior to the focus groups, in response to short questions about the NCSP and their intentions to screen, $62 \%$ $(n=29)$ of women correctly responded that they were in the age eligible for cervical screening and $81 \%(n=38)$ of women correctly responded how often women are invited (table 4$)$. Almost $90 \%(\mathrm{n}=42)$ of women intended to go for cervical screening in the future.

Following the presentation of information about the changes, all women correctly answered when the changes were taking place, with most (>95\%; $n=46-48)$ correctly responding to questions about the age of invitation, screening frequency, that HPV will be tested for, and that the experience will be the same for women after the changes. Fewer women correctly responded that the sample would be tested differently $(68 \% ; n=32)$. Of note, less than $60 \%(n=25)$ of women were aware that you should go for screening when you are healthy, with $36 \%$ $(\mathrm{n}=15)$ believing you should go for cervical screening when you notice abnormal changes. In total, $96 \% \quad(n=46)$ of women intended to screen in the future. 
Table 4 Responses to questions about the cervical screening programme before and after the focus groups

$n *(\%)$

Prior to focus groups (old screening programme)
Are women your age eligible for free cervical
screening? (Yes, no l'm too young or no l'm too
old)
Yes
How often are women invited to attend? (Every 38 (80.9)
1,2 or 3 years)
Every 2 years

Do you intend to go for cervical screening in the 42 (89.4) future (when you do not have symptoms)?

Yes

After the focus groups
When should you go for cervical screening?
(healthy or when noticed symptoms)
When healthy
When are the recommendations for cervical
screening changing? (1 Oct or 1 Dec)
$\begin{aligned} & \text { Wecember } 2017 \\ & \text { What age will women be invited for cervical }\end{aligned}$
$\begin{aligned} & \text { screening after the changes? (18, 20, } 25 \text { or } 30 \\ & \text { years of age) }\end{aligned}$
25 years of age

How often will women be invited for screening 48 (98)
after the changes? (Every 1, 2, 3, 5 or 7 years)
Every 5 years

Will the experience of cervical screening be the 48 (98) same for women after the changes? $(\mathrm{Y} / \mathrm{N})$ Yes

Will the sample taken from the cervix be tested 32 (68.1) in the same way after the changes? $(\mathrm{Y} / \mathrm{N})$

No

The sample from the cervix will be testing for: (abnormal cells or HPV)

HPV

Do you intend to go for cervical screening in the 46 (95.8)
future (when you do not have symptoms)? (Y/N)
Yes

${ }^{*} \mathrm{~N}$ represents the number of women who chose the correct answer for all items apart from intentions for screening in the future. HPV, human papillomavirus.

\section{DISCUSSION}

This study showed that women had little awareness of the changes to the NCSP just prior to their implementation in December 2017. Women expressed concern about the increased screening interval and later age of first screening because of fears about missing cancer, consistent with our previous research. ${ }^{10}{ }^{11}$ Concerns about exit testing were less commonly expressed. However, following the information presented, and given the opportunity to discuss among their peers, many participants understood and accepted the reasons for these changes. The findings suggest that if information and the rationale for change is presented clearly, women will likely accept deintensified screening programmes. This has implications for national programmes worldwide and for screening programmes broadly as well as for cervical screening in Australia.

Clear communication to the public about changes to cervical screening programmes, and what these changes may mean for them, needs to be developed in light of these findings. There also needs to be clear guidance for future changes to cervical screening programmes, which address the differences between the two tests, making it clear that the test is now detecting a virus prior to abnormal cells. Women need to be aware of what HPV is and how it is linked to cervical cancer, including the slow progression of HPV to cervical cancer and the high chances of regression. Importantly, women also want to see evidence behind the changes, such as the incidence of cervical cancer, to reassure them about the changes to screening age targets. Women discussed these concerns within the focus group sessions, and how they processed the information about the natural history of cervical cancer helped them to understand the reasons for the changes in screening interval and the screening test itself.

Our analysis showed that women found certain pieces of the information presented to them useful and reassuring to justify the changes (Natural history, Incidence and Transition to the new programme). The findings from this study demonstrate the fundamental information women extracted to help them make sense of the changes and provides important insights into the lay language women used to explain the changes to each other, which can be used in developing guidance for communication strategies. Overall, women in all age groups expressed similar concerns, but the older women expressed more concern and confusion about the reasons for the exit test, demonstrating areas where communication could be tailored to the different age groups. Both groups of women were concerned about what the changes would mean for the younger age groups. The majority of women still intended to screen following the information, demonstrating their continuing confidence and trust in the programme.

Most of the information presented to women was new, with their views towards screening shaped by the many years of messages focused on the importance of attending screening and that early detection is key in reducing deaths from cancer. These reactions are not surprising given that research has shown a high public enthusiasm for screening, ${ }^{14}{ }^{15}$ with $56 \%$ cervical screening uptake in women aged $20-69,{ }^{16}$ women have spent much of their lives being told about the importance of having regular screening and early detection, and believe "more care is better care' ${ }^{17}$ Awareness of HPV among the general public has been found to be limited in many previous studies, ${ }^{18} 19$ with women in this study being similar. Equipping women with the information about HPV and that the new test was now going to detect infection with the virus, which was seen to be a 'step ahead', was reassuring. Practical information for women, so they could evaluate what this would mean for them, was important, specifically knowing that 
the procedure of the test would be the same, and that the difference lies in how the sample is tested.

The information presented from the Department of Health website ${ }^{20}$ did not specifically mention overdetection but mentioned the possibility of investigating and treating common cervical abnormalities that would usually resolve. The public can be confused by concepts such as overdiagnosis and it has the potential to undermine trust in screening programmes. ${ }^{21}$ Overdetection was briefly mentioned in the information developed by the authors, when talking about the later starting age for screening, with regard to cervical abnormalities regressing and the possibility of overtreatment, which can lead to obstetric complications. This concept was not attended to much by women in the focus groups, with surprise expressed in those who did. It was clear that the concept of regression of cervical abnormalities was not well understood and needs explanation for women. ${ }^{21}$

Screening programmes will continue to need reviewing to ensure benefits outweigh harms and are deemed acceptable to the population, as stated by Wilson and Jungner. ${ }^{3}$ Findings from this study can be used to consider processes for deintensification of screening programmes in the future and how to develop communication strategies so that changes to screening programmes are deemed acceptable to the population. Evident at all stages of the principles of screening is the importance of maintaining public confidence, ${ }^{3}$ strategies for communicating these changes and the reasons behind them in a reassuring way, will help maintain public confidence. Formal invitations for cervical screening through the national register may provide an ideal opportunity for educational information to be distributed alongside the invitations.

These findings demonstrate key information which could be applied to other screening programmes to aid in public understanding about changes to screening programmes. Information about the natural history of the cancer, in addition to information about the prevalence and risks of disease and how to transition from the old to the new programme (NhIT), presented in a clear format, can help the public to understand the reasons for these changes and alleviate concerns. Other countries needing to design communication strategies for deintensified screening should consider involving members of the public in their development to ensure the information presented is meeting information needs and ensuring confidence in the screening programme is maintained. Further quantitative research is needed to test optimum formats for presenting this information.

Elimination of cervical cancer could be a real possibility in the future, ${ }^{22}{ }^{23}$ particularly in Australia where the successful school-based HPV vaccination programme for girls and boys has shown significant reductions of incidence in the vaccine-related HPV genotypes, which are high-risk types for cervical cancer. ${ }^{24}{ }^{25}$ Additionally, the recent approval and implementation of the nonavalent vaccine is likely to reduce the incidence of HPV further. ${ }^{26}$ Therefore, there is the possibility within our lifetime that the NCSP may be phased out entirely. ${ }^{23}$ However, in the meantime, it is necessary to communicate that screening is still important, but that there are potential harms associated with cervical screening, such as overtreatment of abnormalities that may otherwise spontaneously resolve. Information about overdiagnosis has been shown previously to be met with confusion or scepticism. ${ }^{27}$ Future studies may be the best placed to focus on reducing overtreatment of cervical abnormalities, particularly in those women of childbearing age who are most at risk of obstetric complications. ${ }^{28}$ Future research also needs to explore the impact of the renewed screening programme on clinical practice, both at the GP level and referral rates.

These findings make an important and timely contribution to the potential communication strategies for other countries updating their NCSP. The content presented in the focus group sessions represented information available to women at the time and was developed by a multidisciplinary team including a consumer, and reviewed by both clinical independent experts and pilot tested with consumers. The qualitative design of the study allowed us to explore in depth the views and understanding of women of eligible screening age, as well as observing how women communicated the reasons behind the changes to each other. This gave valuable insight into what information is important for reassuring women about the changes.

Recruitment of women through an independent market and social research company enabled the participants to vary in age, education, prior screening and ethnicity. Almost $40 \%$ of the sample were born outside of Australia. As this was a qualitative study, we cannot express the findings as generalisable across the whole population.

There were a few aspects that women asked about which were not addressed during the presentation, such as whether there are different screening recommendations for specific population subgroups including women with a family history of cervical cancer, women who had become sexually active at a young age and immunosuppressed women. We did not want to overload women with information and our research aim was to find out what women understood about the changes following the presentation. Some of these points were raised throughout the sessions, and therefore, were talked about at the end, and it may be that this additional information helped reassure women further that there are processes in place for dealing with exceptional circumstances and it is not a one size fits all approach.

\section{CONCLUSIONS}

Most of the information presented to women in these focus groups was new to them. Key pieces of information about the natural history, incidence of cancer and how to transition across the programme (NhIT), helped to explain the reasons behind the deintensification of the Australian NCSP and can be applied to other screening programmes. This can be provided to women in a concise 
and accessible format accompanying invitations to cervical screening in the future. These findings can be used on a broader level to develop a framework for developing communication strategies around future changes to screening programmes.

Twitter Rachael H Dodd @doddrdodd85, Brooke Nickel @brooke_nickel, Sally Wortley@processofimport, Carissa Bonner@carissa_bon, Jolyn Hersch @ jolynhersch and Kirsten J McCaffery @KirstenMcCaffer

Acknowledgements We thank Karen Canfell, Julia Brotherton and Deborah Bateson for helpful comments on the draft presentation, Taverner Research for recruitment services, Abigail Hatherley for transcription services, Alexandra Barratt, Stacy Carter, Jane Williams for helpful comments on the presentation slides, Jebby Phillips for her input and helpful comments as a consumer representative and all study participants.

Contributors RHD and KJM conceived the study. RHD, SW, CB, JH and KJM were involved in designing the study and developing the methods. RHD coordinated the running of the study and conducted the focus groups, together with $\mathrm{BN}, \mathrm{SW}, \mathrm{CB}$ and JH. RHD and BN read transcripts, developed the analytical framework, and contributed to the analysis. RHD drafted the manuscript. All authors contributed to the interpretation of the analysis and critically revised the manuscript.

Funding This work was supported by an NHMRC Programme Grant (APP1113532). Competing interests None declared.

Patient consent for publication Not required.

Ethics approval The University of Sydney Human Research Ethics Committee reviewed and approved this study (project number 2017/489).

Provenance and peer review Not commissioned; externally peer reviewed.

Data availability statement № data are available.

Open access This is an open access article distributed in accordance with the Creative Commons Attribution Non Commercial (CC BY-NC 4.0) license, which permits others to distribute, remix, adapt, build upon this work non-commercially, and license their derivative works on different terms, provided the original work is properly cited, appropriate credit is given, any changes made indicated, and the use is non-commercial. See: http://creativecommons.org/licenses/by-nc/4.0/.

\section{ORCID iDs}

Rachael H Dodd http://orcid.org/0000-0002-8080-6359

Brooke Nickel http://orcid.org/0000-0002-8100-4278

Sally Wortley http://orcid.org/0000-0003-2519-2582

Carissa Bonner http://orcid.org/0000-0002-4797-6460

Jolyn Hersch http://orcid.org/0000-0001-5225-6639

Kirsten J McCaffery http://orcid.org/0000-0003-2696-5006

\section{REFERENCES}

1. Marmot MGet al. The benefits and harms of breast cancer screening : an independent review. Br J Cancer 2013;108:2205-40.

2 Carter S, Barratt A. What is overdiagnosis and why should we take it seriously in cancer screening? Public Health Res Pract 2017;:27:e2731722.

3. Wilson J, Jungner G. Public health papers; no.34. Principles and practice of screening for disease World Health Organisation; 1968.

4 Dobrow MJ, Hagens V, Chafe R, et al. Consolidated principles for screening based on a systematic review and consensus process. Can Med Assoc J 2018;190:E422-9.

5 Gray JAM, Patnick J, Blanks RG. Maximising benefit and minimising harm of screening. BMJ 2008;336:480-3.
6 National HPV Vaccination Program Register. Coverage data, 2018. Available: http://www.hpvregister.org.au/research/coverage-data

7 Medical Services Advisory Committee.MSAC Application No. 1276. National cervical screening program renewal: evidence review (assessment report); 2013.

8. UK National Screening Committee. Age of first invitation for cervical screening and frequency of invitation for women aged between 50 to 64 years; 2012

9 Davidson AS, Liao X, Magee BD. Attitudes of women in their forties toward the 2009 USPSTF mammogram guidelines: a randomized trial on the effects of media exposure. Am J Obstet Gynecol 2011;205:30. e1-30.e7.

10 Obermair HM, Dodd RH, Bonner C, et al. 'It has saved thousands of lives, so why change it?' content analysis of objections to cervical screening programme changes in Australia. BMJ Open 2018;8:e019171.

11 Dodd RH, Obermair HM, McCaffery KJ. A thematic analysis of attitudes toward changes to cervical screening in Australia. JMIR Cancer 2019;5: e12307-9.

12 Australian Government Department of Health. future changes to cervical screening, 2017. Available: http://www.cancerscreening.gov. au/internet/screening/publishing.nsf/Content/future-changes-cervical [Accessed 12 Apr 2017].

13 QSR. NVivo qualitative data analysis Software Version 11 QSR International Pty Ltd. 2015.

14 Waller J, Osborne K, Wardle J. Enthusiasm for cancer screening in Great Britain: a general population survey. $\mathrm{Br} J$ Cancer 2015;112:562-6.

15. Schwartz LM, Woloshin S, Fowler FJ, et al. Enthusiasm for cancer screening in the United States. JAMA 2004;291:71-8.

16 Australian Institute of Health and Welfare. Cervical screening in Australia 2019, 2019

17 Carman KL, Maurer M, Yegian JM, et al. Evidence that consumers are skeptical about evidence-based health care. Health Aff 2010;29:1400-6.

18. Marlow LAV, Zimet GD, McCaffery KJ, et al. Knowledge of human papillomavirus (HPV) and HPV vaccination: an international comparison. Vaccine 2013;31:763-9.

19 Klug SJ, Hukelmann M, Blettner M. Knowledge about infection with human papillomavirus: a systematic review. Prev Med 2008;46:87-98.

20 Australian Government Department of Health. National Cervical Screening Program. Available: http://www.cancerscreening.gov. au/internet/screening/publishing.nsf/Content/cervical-screening-1. [Accessed 10 Aug 2018].

21 McCaffery KJ, Jansen J, Scherer LD, et al. Walking the tightrope: communicating overdiagnosis in modern healthcare. BMJ 2016;352:i348-5.10.1136/bmj.i348

22 Garland SM, Giuliano A, Brotherton JML, et al. IPVS statement moving towards elimination of cervical cancer as a public health problem. Papillomavirus Research 2018;5:87-8.

23. Hall MTet al. The projected timeframe until cervical cancer elimination in Australia : a modelling study. Lancet Public Heal 2019;4:E19-27.

24 Garland SM, Cornall AM, Brotherton JML, et al. Final analysis of a study assessing genital human papillomavirus genoprevalence in young Australian women, following eight years of a national vaccination program. Vaccine 2018;36:3221-30.

25 Machalek DA, Garland SM, Brotherton JML, et al. Very low prevalence of vaccine human papillomavirus types among 18- to 35 -year old Australian women 9 years following implementation of vaccination. $J$ Infect Dis 2018;217:1590-1600.

26. Brotherton JML. Human papillomavirus vaccination update: nonavalent vaccine and the two-dose schedule. Aust J Gen Pract 2018;47:417-21.

27. Hersch J, Jansen J, Barratt A, et al. Women's views on overdiagnosis in breast cancer screening: a qualitative study. BMJ 2013;346.

28 Arbyn M, Kyrgiou M, Simoens C, et al. Perinatal mortality and other severe adverse pregnancy outcomes associated with treatment of cervical intraepithelial neoplasia: meta-analysis. BMJ 2008;337:a1284-803. 